\title{
The Comparative Effects of English and Persian Cultural Background Knowledge on EFL Learners' Listening Skill
}

\author{
Mulyanto Widodo $\mathbb{D}^{1},{ }^{1}$ Natalya Ryafikovna Saenko $\left(\mathbb{D},{ }^{2}\right.$ Osmer Campos-Ugaz $\mathbb{D}^{3},{ }^{3}$ \\ Miguel A. Saavedra-López $\mathbb{D}^{4},{ }^{4}$ Luis Alberto Núnez Lira $\mathbb{D}^{5},{ }^{5}$ Seyedeh Sahar Razavi $\mathbb{D}{ }^{6}{ }^{6}$ \\ Muhammed Salim Keezhatta $\mathbb{D}^{7},{ }^{7}$ Natalia Fedorova $\mathbb{D}^{8}$ Huynh Tan Hoi $\mathbb{D}$, \\ and Aleksander G. Ilyin $\mathbb{D}^{10}$

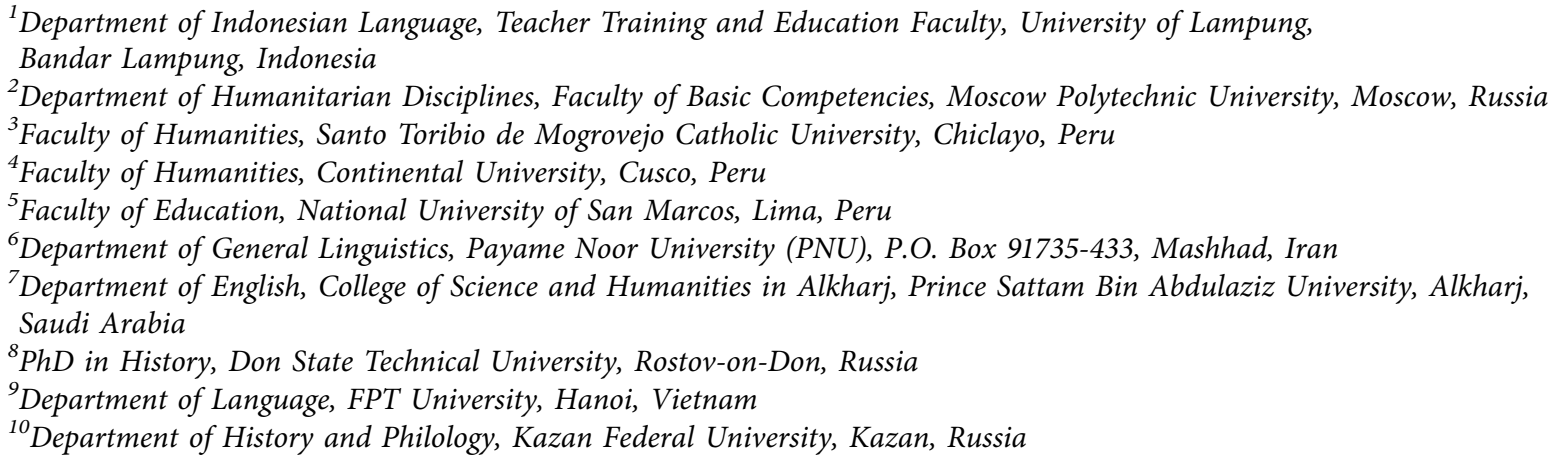

Correspondence should be addressed to Seyedeh Sahar Razavi; s.sahar.razavi@gmail.com

Received 25 September 2021; Accepted 3 February 2022; Published 4 March 2022

Academic Editor: Chan Swee Heng

Copyright $\odot 2022$ Mulyanto Widodo et al. This is an open access article distributed under the Creative Commons Attribution License, which permits unrestricted use, distribution, and reproduction in any medium, provided the original work is properly cited.

\begin{abstract}
This research compared the impacts of Persian and English cultural background knowledge on Iranian EFL learners' listening skill. To that purpose, the Oxford Quick Placement Test (OQPT) was given to 86 Iranian EFL students; 50 of them were chosen as research participants. The respondents were then divided into two equal experimental groups (EGs) at random (Persian culture and English culture). A listening pretest was then given to both groups. The individuals in both EGs were then given the treatment. The researchers taught one EG by using the English cultural materials, while they taught the other group through the Persian cultural materials. The data were analyzed by utilizing paired samples and independent samples $t$-tests after the listening posttest was administered. The results showed that both EGs performed better on their posttests than on their pretests, and that there were no significant differences between the impacts of English cultural background knowledge and Persian cultural background knowledge on the listening skills of EFL students. The implications of this research can persuade EFL English teachers to incorporate more cultural-based materials into their teaching process.
\end{abstract}

\section{Introduction}

Culture has an important role in language learning. Culture is a bond that assists people of a place or a country come together [1]. Being familiar with the target culture (TC) can aid EF students to learn English more efficiently; as Nguyen
[2] mentions, pupils who learn particular cultural knowledge are able to develop more positive attitudes towards the TC, and this helps them learn that language more successfully. Culture has a vital part in language teaching/learning with the aim of improving learners' communicative skills. Language competency and culture are inextricably and 
dynamically interconnected [3-6], because the capability to effective communication in a language necessitates knowledge of perceiving, interpreting, and behaving appropriately in accordance with the culture relevant to the language. As a result, culture should be given adequate attention in language instruction in order to enable learners to interact to the maximum degree possible.

Having cultural knowledge helps make communications in a successful way with other people and not to be misunderstood or misinterpreted [7]. Thus, in teaching English skills, instructors should use cultural-based materials and resources. Being familiar with the TC can assist EFL students in improving their listening skill. The first language skill that students learn is listening as an input skill. It serves as the basis for all elements of linguistic and cognitive growth, and it performs a continuous role in the processes of learning and communication that are necessary for meaningful engagement in life [8-10]. Furthermore, Rost [11] characterizes listening as the process of comprehending what is heard and integrating it into lexical components to which meaning may be ascribed. He believes that learners hear oral communication, separate sounds, categorize them into lexical and syntactic components, and grasp the messages.

Based on Jafari and Hashim [12], listening includes aural discrimination, auditory grammar, choosing needed information, recalling it, and relating it to the process among sounds and forms of meanings, and they highlighted that listening is a pathway for comprehensible inputs and most of the time students spend their time on listening comprehension. According to Hamouda [13], listening comprehension is an active process in which students participate in the construction of meanings. Furthermore, listening comprehension implies that we comprehend what we have heard. We will comprehend the message if he/she learns it by listening to it.

Unfortunately, in language learning process, listening is regarded as the Cinderella skill that has been neglected by its elder sister-speaking. For most individuals, knowing a second language entails being fluent in speaking in that language. Listening and reading are, in essence, secondary skills-means to other purposes rather than ends in themselves $[14,15]$.

Regarding the significance and the effectiveness of cultural background knowledge on English language learning, the current investigation intended to compare the impacts of English and Persian cultural background knowledge on improving Iranian EFL learners' listening skill.

\section{Literature Review}

2.1. Theoretical Background. Language and culture are interrelated; indeed, language learning/teaching and culture are not separated; thus, both target language and culture should be taught simultaneously. Language learning is not only acquiring the main skills (e.g., reading, listening, writing, and speaking) and subskills (e.g., grammar, pronunciation, vocabulary, and so on), but also it is acquiring the cultural contents of that language. According to Hesar and Zarfsaz [16], perfect comprehension of a target language includes not only comprehension of language abilities, structures, and norms, but also knowledge of the TC. Thus, it is necessarily vital for English students to enhance their English cultural knowledge to use English fluently. Kim [17] states that learning a language without comprehending its culture is impossible, and understanding English culture makes learning English language easier.

Cultural awareness entails knowledge and comprehension of other cultural groups' beliefs and conventions, identification of culturally based hypotheses and prejudices, and showing abilities that suit the needs of customers from different cultural backgrounds [18]. Rogatin et al. [19] confirmed the contributions and the effectiveness of culture teaching in the foreign language classrooms. Cultural understanding can help EFL students improve their listening skills. Listening is characterized by Jafari and Hashim [12] as a medium for obtaining comprehensible and intelligible material, suggesting that it is the most utilized ability and hence requires the greatest notice in teaching and learning in EFL contexts. Based on Goss [20], listening is the act of comprehending what is heard and arranging it into particular lexical components from which meanings may be deduced.

In language development, there are three sorts of listening activities: prelistening, while listening, and postlistening. Prelistening activities usually have two important objectives: first, they activate participants' previous knowledge of the language in order to elucidate and improve their expectation and suppositions about what they will hear, and second, they provide the atmosphere required to complete the entangled listening task $[10,21,22]$. Drawing on past knowledge can provide context for the speakers, the primary subject, and the concepts and terminology included in the text, pique learners' attention. Such exercises necessitate well-crafted questions from language teachers in order to employ the linguistic elements required to understand the material. Clearly stated, this stage prepares learners to listen. Furthermore, instructors must be aware of the difficulties learners may encounter, such as dialects, jargon, terminology, and idioms [23, 24].

2.2. Empirical Background. Several empirical investigations were carried out to determine the impacts of cultural knowledge on English language learning. Rashidi and Soureshjani [25] examined if teaching culturally loaded passages to Iranian EFL students affected their achievement on reading comprehension assessments. Furthermore, they explored the probable correlation between the instruction of culturally relevant texts and the language learners' motivation level of learning. To accomplish this, 102 Persian students (from two classes) were chosen using a simple convenience sampling technique. The treatment was administered to the experimental class (teaching culturalbased passages). In addition, they were administered a questionnaire to examine their motivation. The outcomes of the data analysis indicated that teaching cultural components of the target language might bear a significant influence on developing the reading comprehension of the 
students. The findings also revealed that cultural instruction played a significant impact in increasing the motivation of language learners.

Bakhtiarvand and Adinevand [26] inspected the impacts of cultural awareness on improving the Iranian EFL students' listening comprehension. From a sample population of 300 participants, $120 \mathrm{EFL}$ students at the preintermediate level were chosen and randomly divided into four groups. Throughout 16 weeks, each group was exposed to the following conditions: TC, International Target Culture (ITC), Source Culture (SC), and Culture Free (CF). Pretests and posttests consisting of 25 listening comprehension questions were administered with a null hypothesis that none of the conditions would have any remarkable impact on listening comprehension. The outcomes processed by post hoc and one-way ANOVA tests indicated that the TC, ITC, and SC groups had statistically significant gains, while the $\mathrm{CF}$ participants had no significant gains.

Hayati [27] examined the effect of cultural knowledge on the improvement of the Iranian EFL students' listening comprehension. To achieve this goal, 120 EFL students at the preintermediate level were chosen from a population of 300 volunteers according to their performance on a listening skill exam and randomly divided into one of 4 groups. The group was subjected to one of four conditions: TC, ITC, SC, and CF. A listening posttest was given to each of the four groups at the end of the intervention to find out if any improvements had occurred in their listening competence. The findings indicated that the respondents had different performances on the posttest, indicating that acquaintance with culturally based language resources improved the listening competence of Iranian EFL students.

In another research, Davoudi and Ramezani [28] surveyed the effects of cultural familiarity on Iranian EFL students' reading comprehensions. According to the Michigan test results, 60 English as a Foreign Language (EFL) university students were chosen and allocated to two fairly comparable groups, resulting in two complete courses. Both the CG and control group (CG) were given one of the three short tales, and the EG was additionally given the background information passage of the delivered short story. They were instructed to construct free-recall procedures based on what they had read in order to assess their reading comprehension. The recall-protocols were scored using propositional analysis, and this research included two levels of analysis, qualitative and quantitative. The findings revealed that acquaintance with the culture of the target language greatly developed the Iranian EFL students' reading comprehensions significantly.

Karimi and Nafissi [29] investigated the effect of various culturally-oriented texts on EFL college learners' foreign language reading anxiety, reading comprehension self-efficacy, and reading proficiency in project-based classrooms. The study involved two classes of the intermediate level freshmen studying in ELT. The CG had to submit their proposals according to reading texts from the book "Active" (L2 culturally based passages), whereas the EG had to give their proposals based on the researcher's L1 and L2 culturally based reading texts. The reading comprehension self- efficacy scales, foreign language reading anxiety scales, and reading part of the Michigan Test (1998) were given to pupils as the pretest and the posttest at the outset and the end of the academic year comprised of two project-oriented reading courses. The data was analyzed using ANCOVA. Although substantial improvements were found in both groups for the three aforementioned categories, the EG exhibited considerably lower levels of anxiety as compared to the CG. However, there was not a difference in reading self-efficacies or reading proficiencies between the two cohorts.

Al-Khresheh [21] attempted to determine if Saudi EFL learners have specific difficulties with listening comprehension, to uncover probable causes of the difficulties, and to determine if cultural knowledge impacts the listening skill. A triangulation approach was used to achieve these goals. A diagnostic exam and a questionnaire were administered to a group of 31 Saudi English learners, and 8 EFL teachers were asked to write a reflection essay. The outcomes showed, first, that hearing was the most difficult skill of English language to master, and second, that Saudi EFL learners struggled significantly in the perceiving, parsing, and usage phases of their listening skill for a number of justifications. The results also revealed that their cultural awareness had a considerable influence on their listening comprehension.

Regarding the effect of cultural awareness on improving English language skills, the current research was an attempt to compare the impacts of English and Persian cultural background knowledge on developing Iranian EFL learners' listening skill. Having this goal in mind, this research tried to answer the following research question:

RQ. Is there any significant difference between English and Persian cultural background knowledge on developing Iranian EFL learners' listening skill?

\section{Methodology}

3.1. Participants. This research was carried out on $50 \mathrm{stu}-$ dents from Adiban institute in Abadan, Iran. The selected participants were recruited among 86 learners based on their performance in the OQPT. Based on their scores, 50 of them were intermediate students. Respondents with scores ranging from 30 to 47 participated in the research as the intermediate responders. They were assigned in two experimental groups: English culture and Persian culture. They were all females. The respondents ranged in age from 17 to 24 years old.

3.2. Instrumentation. The OQPT was the first tool used in the current investigation to homogenize the subjects. It aided the researcher in determining whatever level (elementary, preintermediate, or intermediate) her subjects were at. This exam consisted of 60 multiple-choice items, and students with scores ranging from 40 to 47 were identified as intermediate learners and chosen as research respondents.

The second information-gathering tool was a researchercreated listening pretest based on learners' coursebook. It was a 40 -item objective listening skill exam. It contained fill- 
in-the-blanks, true/false, and multiple-choice items. The specified test's reliability and validity were assessed. Four professionals reviewed the test after it was built to ensure its content and face validities. To be certain about the Content Validity Index of the exam questions, four experienced English instructors looked over the test and made some adjustments to the readability, clarity, and generalizability of the items. Following that, the test was updated and piloted on a comparable cohort in another institution with the same coursebooks and levels. Following validation and piloting, the required alterations and revisions were performed in the test to attain item attributes such as item facility, item discrimination, and option dispersion. Eventually, the test was ready to administer. Its reliability was determined applying KR-21 $(r=0.81)$.

The third tool used in this research was a researchercreated listening posttest, which was a revised form of the pretest. It was provided to the participants in order to assess the effects of the therapy, namely, the cultural knowledge, on their listening comprehension capacity. In terms of duration and quantity of questions, the posttest had the same features as the pretest. The only difference was that the sequence of the questions and options was modified to eliminate the possibility of remembrance of pretest responses. The posttest validity was verified by four English teachers, and its reliability was calculated by utilizing KR-21 $(r=0.83)$.

3.3. Data Collection Procedures. In the first stage, 86 students from a private English language institution in Abadan, Iran, were given OQPT. Fifty intermediate students were chosen as research participants based on their achievement in the aforementioned test. Following the selection of the targeted respondents, they were separated into two experimental groups. After that, the researchers employed a related listening pretest to the both groups, and then, they started to apply the treatment. The researchers taught the English culture group by using the target cultural materials, while they taught the Persian culture group through Persian cultural materials. The audio files, which were played in the first experimental group's class, were original and contained English cultural contents and issues. On the other side, the audio files that were played in the second group's class were local (Persian) and contained contents and issues related to the Persian culture. The treatment took ten sessions, with each session lasting 50 minutes. The participants were homogenized in the first session; the target respondents were pretested in the second session; and the researcher taught listening skills to both groups of students over the course of seven sessions. The researcher gave the listening posttest in the last session to assess the potential effect of the treatments on the participants' listening progress.

3.4. Data Analysis. Data collected using the aforementioned devices was evaluated and interpreted in accordance with the study's goals. Firstly, to check the quality of data normality before running statistical tests, the students' scores on listening pretest and posttest were depicted on normal distribution curve. For normality, Kolmogorov-Smirnov (K-S)
TABLE 1: Descriptive statistics (pre-test of both groups).

\begin{tabular}{ccccc}
\hline Groups & $N$ & Mean & Std. deviation & Std. error mean \\
\hline Persian & 25 & 14.08 & 2.28 & 0.46 \\
English & 25 & 13.84 & 2.74 & 0.53 \\
\hline
\end{tabular}

test was utilized. Then, an independent sample $t$-test was used to assess the impacts of the intervention, cultural knowledge, on the participants' listening skill.

\section{Results of the Study}

The Statistical Package for Social Science (SPSS) software version 22 was utilized to analyze the collected data. The results of the K-S test indicated that the statistics of the scores were normal; consequently, the parametric statistics such as independent samples $t$-test were utilized to gain the final outcomes in this research.

Table 1 displays the descriptive data for both groups. The mean score and standard deviation for the Persian group are 14.08 and 2.28, respectively. The English group's mean score and the related standard deviation are 13.84 and 2.74, respectively. This indicates that both groups are comparable in certain ways because they are homogenous at the outset of the instruction.

The scores of both groups on the pretest were shown in Table 2 using an independent samples $t$-test. Because Sig $(0.90)$ is larger than 0.05 , the differences between groups are not statistically remarkable at $(p=0.05)$. They did, in fact, equally in the listening pretest.

The descriptive data for both groups in the posttest are displayed in Table 3. The Persian group has a mean score of 16.52, whereas the English group has a mean score of 17.80. An independent samples $t$-test was performed to determine if the differences between the posttests of the two groups were significant.

Table 4 shows that the differences between the two groups are not statistically considerable $(p 0.05)$. In the listening posttest, both groups performed equally.

\section{Discussion and Conclusion}

After evaluating the data and getting the findings, the researcher moves on to the discussion part to respond to the questions and compare and contrast them with previous researches. According to the present study's findings, both EGs had greater listening scores on their posttests. There were substantial differences between each group's pre- and posttests.

Familiarity with English culture helped Iranian EFL students enhance their listening skill. Rashidi and Soureshjani [25], who performed a study on the effects of cultural background on EFL students' reading comprehension, confirm the outcomes of this research. The findings indicated that teaching target language cultural components can have a significant influence on language students' performance on reading comprehension tests. The research also revealed that cultural education had a significant impact in increasing the language learners' motivation. 
TABLE 2: Independent Samples $t$-test (Pretest of Both Groups).

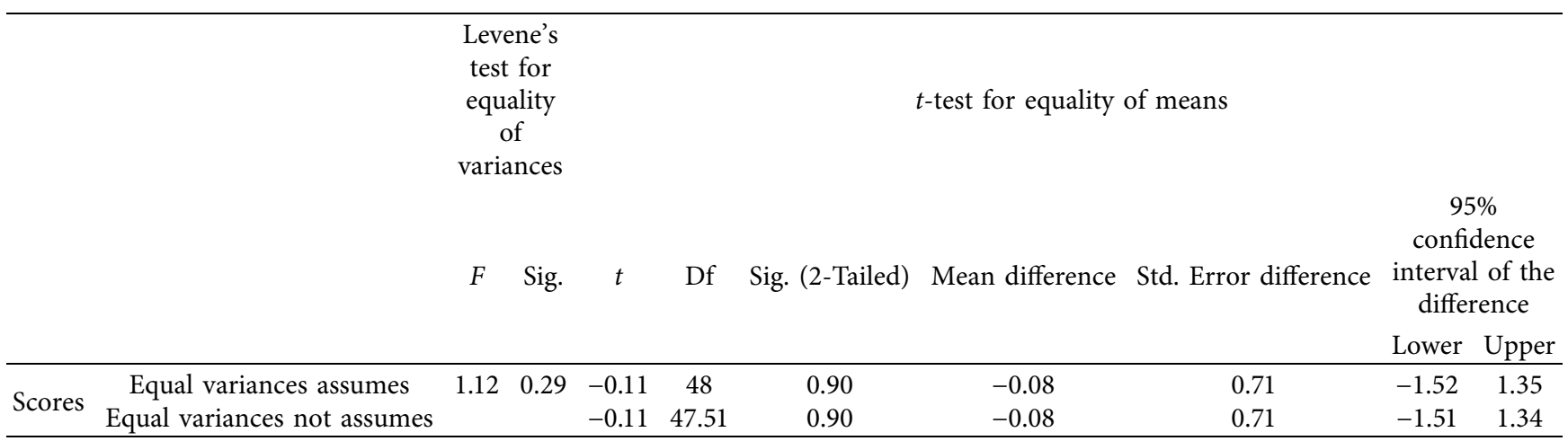

TABle 3: Descriptive statistics (posttest of both groups).

\begin{tabular}{ccccc}
\hline Groups & $N$ & Mean & Std. deviation & Std. error mean \\
\hline Persian & 25 & 16.52 & 2.59 & 0.53 \\
English & 25 & 17.80 & 1.46 & 0.28 \\
\hline
\end{tabular}

TABLe 4: Independent Samples $t$-test (the Posttest of Both Groups).

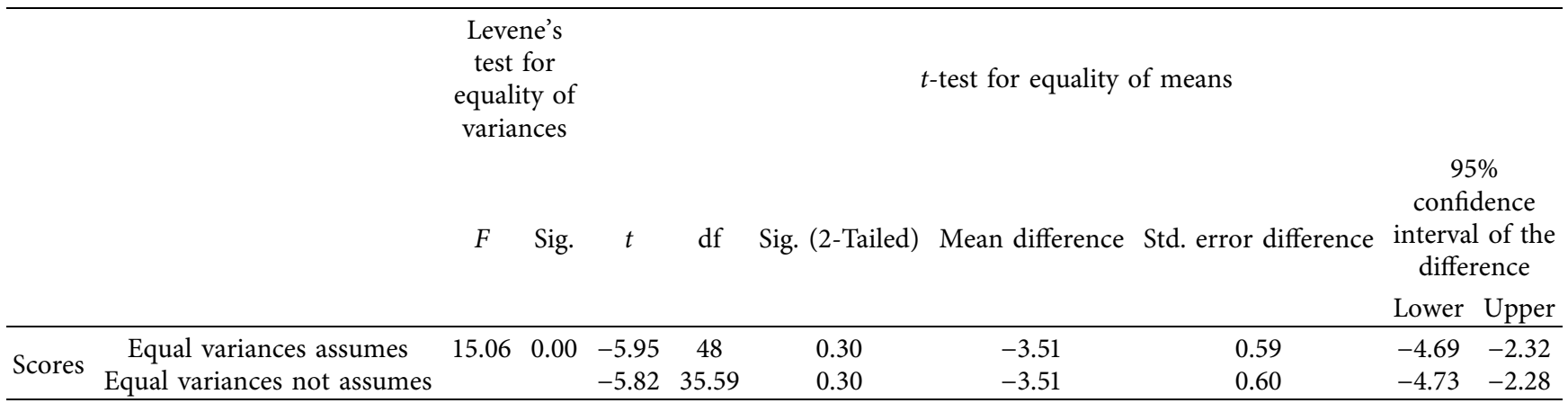

The findings of the present study are in agreement with Zarei and Mahmudi [30] who inspected the effects of schema building activities on Iranian EFL students' listening and reading skills. Their findings revealed that the schema groups outperformed the control group in listening and reading posttests. In fact, our study is supported by the theory of schemata activation. Bilokcuoglu [31] stated that the activation of background knowledge can lead to a successful language learning. In schemata activation pupils rely on their prior knowledge about the texts and connect new information to their background knowledge, and this connection results in learning English language.

Hayati [27], who studied the influence of cultural information on improving Iranian EFL students' listening skill, similarly supports this research. A posttest was given to each of the 4 groups at the conclusion of the research to assess if there had been any improvements in their listening competence. The findings showed that respondents performances were different in the posttests, showing that acquaintance with culturally based contents improved the listening competence of Iranian EFL students.
The results of this investigation are in agreement with Davoudi and Ramezani [28] who explored the role of cultural familiarity on reading comprehension of Iranian EFL students. The results showed that acquaintance with the culture of the target language significantly enhanced reading comprehension. Furthermore, the findings are consistent with those of Yousef, Karimi, and Janfeshan [32], who studied the link between Iranian EFL learners' cultural backgrounds and reading comprehension. The results revealed that the mean of all groups in culturally familiar reading test was higher than their mean in unfamiliar reading test.

Based on Hayati [27], students' cultural knowledge is the foundation for language learning. He maintained that when students gain sufficient target cultural knowledge, they can professionally learn that language. Advocators of the background knowledge say that activating background knowledge and relating novel information to the previous information can result in language learning. Learners will not understand the new listening passage if they do not have associated information about various subjects in their minds [31]. 
The present study compared the effects of English and Persian cultural background knowledge on Iranian EFL students' listening skill. The outcomes showed that both English and Persian cultural background knowledge improved Iranian EFL learners' listening skill equally. Language learners who wish to enhance their listening skills should be exposed to more target culture and ICT resources. Language learners need to develop their English learning by increasing their interaction to certain culturally focused resources, such as English culture resources. Background knowledge, cultural familiarity, and language complexity are critical linguistic and meta-linguistic features for improving English acquisition. As a result, access to language resources in which these three characteristics are prominent can improve Iranian EFL learners' listening skills.

This study has some implications for EFL learners, teachers, and material developers. Regarding the effectiveness of cultural background knowledge on Iranian EFL learners' listening skill, teachers can activate EFL learners' cultural schema before writing, reading, listening, and speaking activities. Teachers can teach those topics that contain some cultural issues in order to provide cultural background knowledge for their students. The outcomes of this research can inspire EFL learners to expose themselves to target culture materials frequently. By having more exposures to cultural-based materials, EFL learners can enhance their English learning. In addition, the outcomes of this investigation can persuade the material developers to integrate more English culturally based contents into the Iranian EFL syllabuses.

Limitations are unavoidable in any research study. Only 50 EFL learners were included in this study; future studies can include more participants in order to increase their findings' generalizability. The researchers of this study could collect only quantitative data to answer the research question; future investigations are offered to use both qualitative and quantitative data in order to enrich the validity and reliability of their results. This study was done in an EFL context, and future studies can be done in ESL contexts to investigate the effect of cultural background knowledge on other skills and subskills of English language. This study was conducted on intermediate EFL learners, and upcoming studies can work the similar topics on other language proficiency levels (upper-intermediate and advanced).

\section{Data Availability}

The data are available through direct contact with the corresponding author for logical reasons.

\section{Ethical Approval}

The studies involving human participants were reviewed and approved by the staff of Iranian Language Institutions. Written informed consent to participate in this study was provided by the participants. The Iranian language institutions follow approved ethical standards, which are in line with the protocols of national research committee and are comparable with the 1963 Helsinki declaration and its later amendments.
Regarding the ethics approval number, it must be noted that, in order to carry out the study and to gather the required data in Iran, institutional ethical values must be obtained from the institution in which the study is initiated. Since the study was conducted in the private sector, no ethics approval number is assigned to the studies in social sciences fields in Iran. In our country, the ethics approval numbers are merely given to the studies in clinical and medical branches of science. However, we reiterate that the institutional as well as individual consents were obtained. The individual consent forms were distributed among the participants. They were given the opportunity to withdraw from the study at any time they intended to. The participants were also reassured they would remain anonymous, and the results would be used for research purposes only. The teachers in the study also signed the consent form and were willing to gather the required data.

\section{Conflicts of Interest}

The authors declare that they have no conflicts of interest.

\section{References}

[1] Y. Lu, "Influence of cultural background knowledge on English reading," Culture and Social Development, vol. 1, no. 1, pp. 46-50, 2018.

[2] L. T. Nguyen, Integrating Culture into Vietnamese University EFL Teaching: A Critical Ethnographic Study, Unpublished PhD Thesis, Auckland University of Technology, Auckland, New Zealand, 2013.

[3] A. A. A. Ahmed and A. Ganapathy, "Creation of automated content with embedded artificial intelligence: a study on learning management system for educational entrepreneurship," Academy of Entrepreneurship Journal, vol. 27, no. 3, pp. 1-10, 2021.

[4] M. A. Melhem, "The Impact of assertiveness training on improving social efficacy among higher basic stage bullied students," Educational Sciences: Theory and Practice, vol. 21, no. 3, pp. 27-39, 2021.

[5] S. M. Mousavi-Davoudi, H. A. Ebrahimian, F. Nasiri-Amiri, and F. Mousavi-Davoudi, "The tendency of authorities towards aristocratic life and its role in the perception of social justice and religion avoidance of students in medical sciences universities," Journal of Pizhūhish dar dìn va salāmat, vol. 6, no. 4, pp. 71-87, 2021.

[6] M. V. Rodriques, Perspectives of Communication and Communicative Competence, Concept, New Delhi, India, 2000.

[7] A. Mohammed, "The impact of culture on English language learning," International Journal on Studies in English Language and Literature, vol. 8, no. 1, pp. 21-27, 2020.

[8] A. Barron-Gutty and S. Chupradit, The Implementation of the Local Content Provision in Thai Basic Education, CELS Centre for Education and Labour Studies, Faculty of Education, Chiang Mai University, Chiang Mai, Thailand, 2009.

[9] N. S. C. Ismail and A. A. Aziz, "The teaching of listening strategies in ESL classrooms," International Journal of Academic Research in Business and Social Sciences, vol. 10, no. 6, pp. 197-209, 2020.

[10] K. Seneviratne, J. A. Hamid, A. Khatibi, F. Azam, and S. Sudasinghe, "Multi-faceted professional development designs for science teachers' self-efficacy for inquiry-based 
teaching: a critical review," Universal Journal of Educational Research, vol. 7, no. 7, pp. 1595-1611, 2019.

[11] M. Rost, Teacher Development Interactive: Listening, Pearson Longman, White Plains, NY, USA, 2009.

[12] K. Jafari and F. Hashim, "Comparison of normal and moderately slow speech rates: listening to students' voices in listening comprehension classes in EFL context," International Journal of Foreign Language Teaching in the Islamic World, vol. 3, no. 3, pp. 5-11, 2015.

[13] A. Hamouda, "An investigation of listening comprehension problems encountered by Saudi Students in the EL listening classroom," International Journal of Academic Research in Progressive Education and Development, vol. 2, no. 2, pp. 113-155, 2013.

[14] G. C. Magulod, L. B. Capulso, J. Pineda Dasig et al., "Attainment of the immediate program graduate attributes and learning outcomes of teacher candidates towards global competence initiatives," International Journal of Learning, Teaching and Educational Research, vol. 19, no. 12, pp. 106125,2020

[15] D. Nunan, "Communicative tasks and the language curriculum,” TESOL Quarterly, vol. 25, no. 2, pp. 279-295, 1991.

[16] M. Hesar and E. Zarfsaz, "Why and how to apply culture in an EFL classroom?" International Conference on Language, Medias and Culture, vol. 33, pp. 68-72, 2012.

[17] D. Kim, "Learning language, learning culture: teaching language to the whole student," ECNU Review of Education, vol. 3, no. 3, pp. 519-541, 2020.

[18] R. Lemmon and D. Jackson-Bowen, "Reality versus perception of cultural competency in speech-language students," Journal of the National Society of Allied Health, vol. 3, pp. 61-74, 2013.

[19] V. Rogatin, R. Nabiev, and E. Rogatina, "The impact of cultural familiarity on learning foreign language among advanced students in Ukraine," Journal of Research in Applied Linguistics, vol. 10, pp. 1337-1348, 2019.

[20] B. Goss, "Listening as information processing," Communication Quarterly, vol. 30, pp. 304-307, 1982.

[21] M. Hamad Al-khresheh, "The impact of cultural background on listening comprehension of Saudi EFL students," Arab World English Journal, vol. 11, no. 3, pp. 349-371, 2020.

[22] H. R'boul, "Intercultural communication dialectics in English language teaching," International Journal of Society, Culture \& Language, vol. 9, no. 1, pp. 30-42, 2021.

[23] I. Kazouz, "An investigation of listening problems encountered by EFL learners: a case study of second year license of English at UKMO," Unpublished Master's Thesis, University of Ouargla, Ouargla, Algeria, 2014.

[24] M. Khoshsaligheh, S. Ameri, F. Shokoohmand, and M. Mehdizadkhani, "Subtitling in the Iranian mediascape: towards a culture-specific typology," International Journal of Society, Culture and Language, vol. 8, no. 2, pp. 55-74, 2020.

[25] N. Rashidi and H. K. Soureshjani, "The effect of teaching culturally-based texts on the Persian English as a foreign language (EFL) learners' motivation and reading performance," Journal of Language Culture, vol. 2, pp. 141-147, 2011.

[26] M. Bakhtiarvand and S. Adinevand, "RETRACTED: is listening comprehension influenced by the cultural knowledge of the learners? A case study of Iranian EFL pre-intermediate learners," RELC Journal, vol. 42, no. 2, pp. 111-124, 2011.

[27] M. Hayati, "The impact of cultural knowledge on listening comprehension of EFL learners," English Language Teaching, vol. 2, no. 3, pp. 144-152, 2014.
[28] F. Davoudi and Z. Ramezani, "Effects of different culturallybased materials on EFL learners' reading anxiety, reading selfefficacy, and reading proficiency in project-based classes," Issues in Language Teaching, vol. 6, no. 1, pp. 83-115, 2014.

[29] F. Karimi and Z. Nafissi, "Effects of different culturally-based materials on EFL learners' reading anxiety, reading self-efficacy, and reading proficiency in project-based classes," Issues in Language Teaching, vol. 6, no. 1, pp. 83-115, 2017.

[30] A. A. Zarei and M. Mahmudi, "The effects of content, formal, and linguistic schema building activity types on EFL reading and listening comprehension," Teaching English Language, vol. 6, no. 2, pp. 79-101, 2012.

[31] H. Bilokcuoglu, "A schematic approach to teaching listening comprehension," ELU Journal of Sciences, vol. 1, no. 6, pp. 76-87, 2014.

[32] H. Yousef, L. Karimi, and K. Janfeshan, "The relationship between cultural background and reading comprehension," Theory and Practice in Language Studies, vol. 4, no. 4, pp. 707-714, 2014. 